\title{
Direct n.c.a. radioiodination of weakly activated arenes using metal salts ${ }^{\dagger}$
}

\author{
By E. Mennicke, M. H. Holschbach and H. H. Coenen* \\ Forschungszentrum Jülich GmbH, Institut für Nuklearchemie, D-52425 Jülich, Germany
}

(Received December 16, 1999; accepted in revised form January 24, 2000)

Direct radioiodination / n.c.a. labelling / Electrophilic substitution / Weakly activated arenes / Metal salts / Trifluoroacetyl hypoiodite

\begin{abstract}
Summary. The direct electrophilic no-carrier-added (n.c.a.) aromatic radioiodination was examined using various metal salts in trifluoroacetic acid (TFA) as in situ oxidation agents. Two different types of metal salts were used comprising TFAsoluble $\left(\mathrm{Pb}\left(\mathrm{CH}_{3} \mathrm{CO}_{2}\right)_{4}, \mathrm{Mn}\left(\mathrm{CH}_{3} \mathrm{CO}_{2}\right)_{3}, \mathrm{KMnO}_{4}, \mathrm{Tl}\left(\mathrm{CF}_{3} \mathrm{CO}_{2}\right)_{3}\right.$, $\left.\mathrm{AgCF}_{3} \mathrm{SO}_{3}\right)$ and TFA-insoluble $\left(\mathrm{Ce}\left(\mathrm{CF}_{3} \mathrm{SO}_{3}\right)_{4}, \mathrm{RuCl}_{3}, \mathrm{FeBr}_{3}\right.$, $\mathrm{K}_{2} \mathrm{Cr}_{2} \mathrm{O}_{7}$ ) salts. Optimization of both labelling systems has been performed using $\mathrm{Pb}\left(\mathrm{CH}_{3} \mathrm{CO}_{2}\right)_{4}, \mathrm{Ce}\left(\mathrm{CF}_{3} \mathrm{SO}_{3}\right)_{4}$ and benzene as a model substrate. At room temperature, the one-pot synthesis was completed within $15 \mathrm{~min}$, resulting in a radiochemical yield of $82 \%$ and $64 \%$ using $\mathrm{Pb}\left(\mathrm{CH}_{3} \mathrm{CO}_{2}\right)_{4}$ and $\mathrm{Ce}\left(\mathrm{CF}_{3} \mathrm{SO}_{3}\right)_{4}$, respectively. Radioiodination of weakly activated monosubstituted benzene derivatives led to high radiochemical yields of about $80 \%$ and $60 \%$ of the corresponding ortho- and para-radioiodo-isomers using both salts. Weakly deactivated chlorobenzene could only be radioiodinated with $\mathrm{Ce}\left(\mathrm{CF}_{3} \mathrm{SO}_{3}\right)_{4}$ as oxidant, forming exclusively the para-product with a radiochemical yield of about $35 \%$. Using the optimized reaction parameters for the other TFA-soluble and -insoluble metal salts with benzene and toluene good radiochemical yields were obtained in all cases except for the manganese and silver salts. Apparently their oxidation power was not strong enough for the radioiodination of the non-activated benzenes. In situ formed trifluoroacetyl $\left[{ }^{131} \mathrm{I}\right]$ hypoiodite is discussed with regard to the reaction mechanism.
\end{abstract}

\section{Introduction}

Iodine isotopes such as iodine-120, $-123,-124$, and partly -131 have nuclear decay properties which permit their in vivo application by preparation of diagnostic imaging agents for positron or single-photon emission tomography (PET or SPECT) [1, 2]. In addition, longer lived iodine125 plays an indispensable role in biomedical research and in vitro diagnosis. Radioiodination of tracer for in vitro and in vivo applications should be rapid and result in a high radiochemical yield (RCY) and high specific activity. Due to the stability of the aromatic carbon-iodine bond radioiodine should be, whenever possible, introduced into an

\footnotetext{
Dedicated to the memory of Professor Alfred P. Wolf.

* Author for correspondence

(E-mail: H.H.Coenen@fz-juelich.de).
}

aromatic moiety of the tracer, which in most cases is performed via electrophilic aromatic substitution. Application of metal salts for radioiodination purposes was rather scarce after some early studies in the seventies. This was probably due to the availability of mild organic oxidation agents like Chloramine- $\mathrm{T}$, Iodogen ${ }^{\mathrm{TM}}$ and $\mathrm{N}$-chlorosuccinimide, which are effectively used for radiolabelling of activated arenes $[3,4]$.

However, the rather neglected approach to generate electrophilic iodine for preparative iodination by metal salts as oxidants still holds high potential. Salts like lead(IV) acetate, ammonium cerium(IV) sulfate and nitrate; manganese(III) acetate, cobalt(III) acetate [5-8], thallium(III) trifluoroacetate [9], silver(I) trifluoromethanesulfonate [10], silver trifluoroacetate [11], potassium permanganate [12], chromium(VI) oxide [13] and potassium dichromate [14] have already been described as oxidants for direct iodination of activated and deactivated monosubstituted arenes on a preparative scale. Many of those iodination reactions were performed in trifluoroacetic acid (TFA), trifluoromethanesulfonic acid or sulfuric acid as solvents, since it is known, that the oxidizing power of metal salts is considerably increased in the presence of strong acids [15].

Recently it has been reported that thallium(III) trifluoroacetate in combination with TFA can even be used for direct n.c.a. radioiodination of weakly activated and nonactivated arenes $[16,17]$. In order to find new oxidants for the n.c.a. radioiodination of aromatic systems the potential of various metal salts in TFA as solvent was studied in this paper. It reports on the results of a comparative radioiodination study using lead(IV) acetate, cerium(IV) trifluoromethane-sulfonate (cerium(IV) triflate), manganese(III) acetate, thallium(III) trifluoracetate, iron(III) bromide, ruthenium(III) chloride, silver(I) trifluoromethanesulfonate, potassium permanganate and potassium dichromate as oxidizing agents. Benzene was chosen as non-activated model compound for comparison of the metal salts and optimizing the reaction parameters. Other simple monosubstituted arenes were used in order to study selectivity and reactivity effects.

\section{Experimental}

\section{Materials and methods}

Metal salts, sodium cyanoborohydride, monosubstituted arenes and the ortho-, meta- and para-iodinated isomers 
were obtained from Aldrich (Steinheim, Germany). Trifluoroacetic acid (TFA) and acetic acid were purchased form Merck (Darmstadt, Germany). $\mathrm{Na}^{131}$ I, Product Code IBS 30, was obtained from Amersham Buchler (Braunschweig, Germany). All other solvents and reagents used were purchased from commercial sources in the highest purity available and were used without further purification.

Analyses of the total radiochemical yields of all radioiodinated arenes were performed by radio-HPLC using a Knauer pump (Typ 64) and a Knauer UV/vis photometer with a detector wavelength of $254 \mathrm{~nm}$. Sample injection was accomplished by a Rheodyne-Injector block (7125). For continuous measurement of radioactivity the outlet of the UV detector was connected to a $\mathrm{NaI}(\mathrm{Tl})$ well type scintillation detector and the recorded data were processed by a software system (Nuclear Interface, Münster, Germany). The radiochemical yield was calculated in terms of percentage of total radioactivity in the injected sample. For the determination of the total radiochemical yield (sum of isomers) a Multosorb RP-18 $(250 \times 4 \mathrm{~mm})$ column was used. On this column also the isomeric distribution of the radioiodinated derivatives of phenol, benzene, chlorobenzene and nitrobenzene was determined using a mobile phase consisting of various concentrations of methanol in water at a flow rate of $1.0 \mathrm{~mL} / \mathrm{min}$. Separation of the radioiodinated isomers of benzamide and benzoic acid was performed using a Cyclobond III $/ \alpha$-Cyclodextrin $(250 \times 4 \mathrm{~mm})$ column with a mobile phase of various concentrations of acetonitrile in water at a flow rate of $1.0 \mathrm{~mL} / \mathrm{min}$.

The radioiodinated isomers of toluene and anisole were analyzed by radio-gaschromatography (radio-GC) using a Hewlett Packard research chromatograph HP 6890 Series. The individual peaks were discontinuously trapped on charcoal. The iodinated anisole isomers were separated on a glass column (4 m length, $4 \mathrm{~mm}$ i.d.) filled with $6 \%$ Bentone-38 and $20 \%$ silicone oil on 60-80 mesh Chromosorb W-AW-DMCS [18]. The separation of the iodinated toluene isomers was performed using a glass column $(8 \mathrm{~m}$ length, $4 \mathrm{~mm}$ i.d.) filled with $20 \%$ azoxydianisole on Chromosorb W-AW-DMCS (60-80 mesh) [19]. The collected peak fractions were measured in a well-type Auto-Gamma Scintillation Spectrometer (Packard, Model 5375).

\section{Radiolabelling}

About $2 \mu \mathrm{L}$ of a n.c.a. $\mathrm{Na}^{131}$ I solution (typically containing $1 \mathrm{MBq}[\cong 27 \mu \mathrm{Ci}]$ ) and in the case of TFA-soluble metal salts sodium bromide $(200 \mathrm{mM}$ in $2 \mathrm{~N} \mathrm{NaOH}, 5 \mu \mathrm{L})$ was placed in a conical $2 \mathrm{~mL}$ reaction vessel equipped with a magnetic stirring bar and a Teflon-rubber septum and dried under a flow of Ar. Using TFA-soluble metal salts defined amounts of the aromatic educt and of the desired metal salt each in $150 \mu \mathrm{L}$ TFA were added successively to start the reaction. In the case of TFA-insoluble metal salts a defined amount of the solid metal salt was placed in the reaction vessel and a defined amount of the aromatic educt in $300 \mu \mathrm{L}$ TFA was added to start the reaction. After stirring for the desired reaction time at room temperature, a $20 \mu \mathrm{L}$ aliquot of the reaction mixture was transferred into a vial containing tetrahydrofurane $(150 \mu \mathrm{L})$ and was subsequently

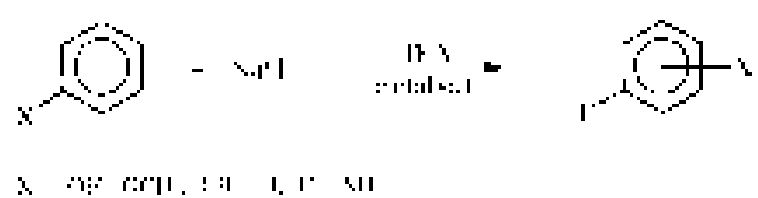

Scheme 1. N.c.a. radioiodination of monosubstituted arenes using various metal salts in TFA.

quenched with sodium cyanoborohydride $(50 \mathrm{mM}$ in $2 \mathrm{~N}$ $\mathrm{NaOH}, 150 \mu \mathrm{L}$ ). After neutralizing with acetic acid the resulting mixture was analyzed by radio-HPLC or radio-GC.

\section{Results and discussion}

Recently the successful use of thallium(III) trifluoroacetate in TFA as an iodination reagent for the radioiodination of weakly and non activated arenes was proven under n.c.a. conditions. Labelling of anisole, toluene and benzene led to radiochemical yields of about $80 \%, 65 \%$ and $40 \%$, respectively $[16,17]$. Since a lot of other metal salts have already been described as iodination reagents for simple monosubstituted arenes on an equimolar scale [5-15], it was stimulating to evaluate their potential for the radioiodination of weakly and non-activated arenes on the n.c.a. level (Scheme 1). Among several strong acids like perchloric acid, sulfuric acid and trifluoromethanesulfonic acid, and polar solvents such as acetonitrile and ethanol, TFA was proven to be the best solvent for the labelling synthesis.

In this study two different types of metal salts were used comprising TFA-soluble $\mathrm{Pb}\left(\mathrm{CH}_{3} \mathrm{CO}_{2}\right)_{4}, \mathrm{Mn}\left(\mathrm{CH}_{3} \mathrm{CO}_{2}\right)_{3}$, $\mathrm{KMnO}_{4}, \mathrm{Tl}\left(\mathrm{CF}_{3} \mathrm{CO}_{2}\right)_{3}$ and $\mathrm{AgCF}_{3} \mathrm{SO}_{3}$ and TFA-insoluble $\mathrm{Ce}\left(\mathrm{CF}_{3} \mathrm{SO}_{3}\right)_{4}, \mathrm{RuCl}_{3}, \mathrm{FeBr}_{3}, \mathrm{~K}_{2} \mathrm{Cr}_{2} \mathrm{O}_{7}$. To show the potential of both types of radioiodination agents in most cases the same metal salts were used as indicated in the literature [5-15]. The influence of different anions of the metal salts on the labelling synthesis was not examined. With the examples of TFA-soluble lead(IV) acetate and TFA-insoluble cerium(IV) triflate the scope of both labelling systems was investigated using benzene as a non-activated model compound. In the case of lead(IV)acetate n.c.a. radioiodination led to the formation of an unidentified side product, which could be avoided by addition of bromide as non-isotopiccarrier. Therefore in this mechanistic study all radioiodination reactions mediated by TFA-soluble metal salts were performed by adding $1 \mu \mathrm{mol}$ of $\mathrm{NaBr}$, except for those on the dependence of added $\mathrm{NaI}$ carrier.

\section{Examination of reaction parameters}

The dependence of the radiochemical yield on the reaction time is shown in Fig. 1. The radioiodination with both lead(IV) acetate and cerium(IV) triflate was very fast and resulted in maximum radiochemical yields of $83 \%$ and $62 \%$, respectively, already after 5 minutes. Extended reaction times had no influence on the formation of $\left[{ }^{131} \mathrm{I}\right]$ iodobenzene.

The influence of the amount of oxidizing agent on the radiochemical yield of $\left[{ }^{131} \mathrm{I}\right]$ iodobenzene is graphically depicted in Fig. 2. These experiments are important in order to determine the minimum amount of the oxidizing agent 


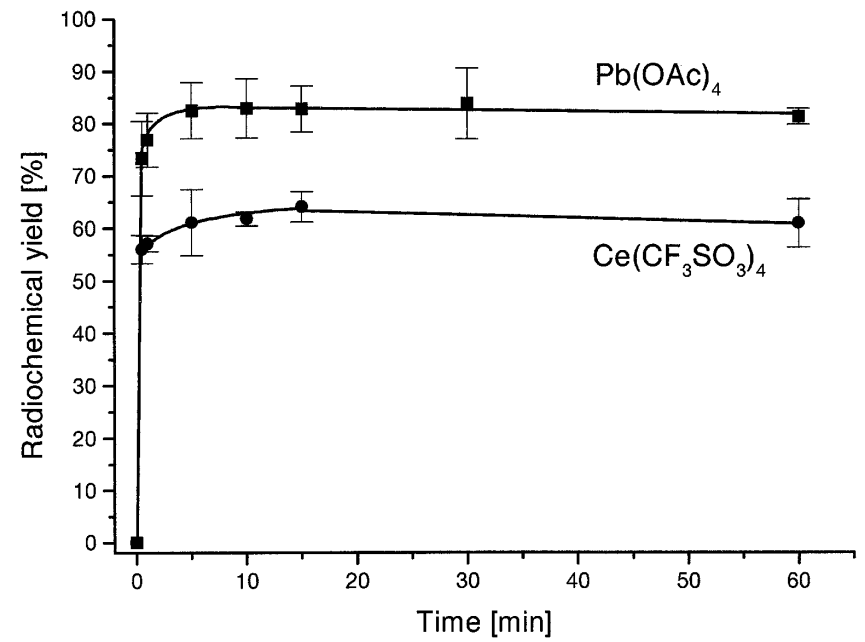

Fig. 1. Radiochemical yields of $\left[{ }^{131} \mathrm{I}\right]$ iodobenzene as a function of time. Reaction conditions: $6.75 \mu \mathrm{mol} \mathrm{Pb}\left(\mathrm{CH}_{3} \mathrm{CO}_{2}\right)_{4}, \quad 22.5 \mu \mathrm{mol}$ $\mathrm{Ce}\left(\mathrm{CF}_{3} \mathrm{SO}_{3}\right)_{4}, 7.5 \mu \mathrm{mol}$ benzene, $0.3 \mathrm{~mL}$ TFA, RT.

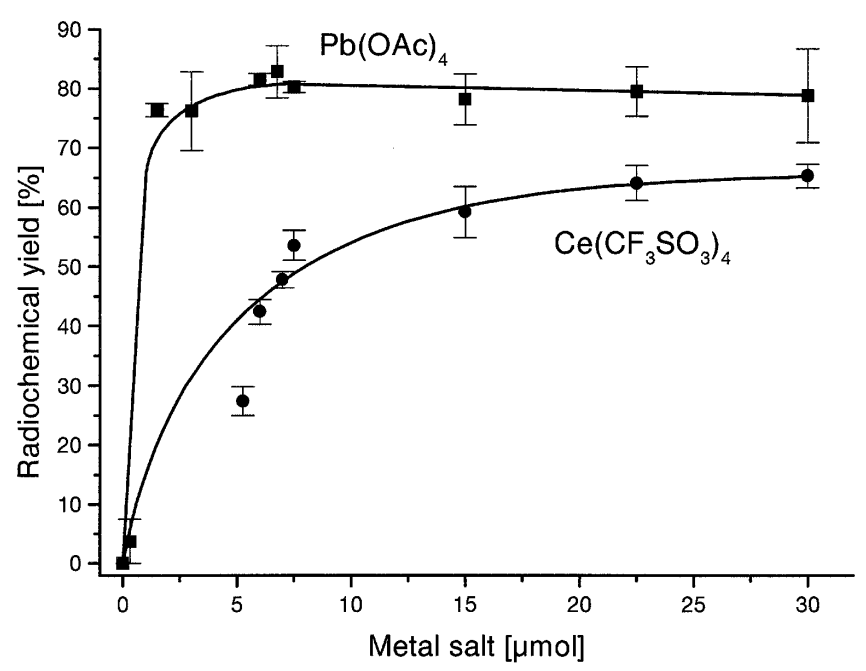

Fig. 2. Dependence of the radiochemical yield of $\left[{ }^{131} \mathrm{I}\right]$ iodobenzene on the amount of lead(IV)acetate and cerium(IV)triflate. Reaction conditions: $7.5 \mu \mathrm{mol}$ benzene, $0.3 \mathrm{~mL}$ TFA, $15 \mathrm{~min}$ at RT.

necessary, because lead(IV) and cerium(IV) salts can cause oxidation of numerous functional groups of given educts [20-23]. Furthermore, the differences between TFA-soluble lead(IV) acetate and TFA-insoluble cerium(IV) triflate are obvious from Fig. 2, since the amount of oxidant for obtaining the optimum radiochemical yield of $\left[{ }^{131} \mathrm{I}\right]$ iodobenzene is five times higher for the insoluble cerium salt than for lead(IV) acetate. Using about $5 \mu \mathrm{mol}$ lead(IV) acetate a maximum yield of about $82 \%$ was found. In the case of cerium(IV) triflate a saturation yield of $64 \%$ was observed using about $25 \mu \mathrm{mol}$. High amounts of cerium(IV) triflate seem to be necessary to raise the reaction rate by increasing the surface of the insoluble metal salt. Moreover, cerium(IV) triflate is a one electron oxidant in contrast to lead(IV) acetate, which removes two electrons at the same time. Therefore, in order to obtain the same reaction rate the amount of cerium(IV) triflate must be at least twice as much as that using lead(IV) acetate.

Low educt concentrations are desirable in order to facilitate product separation and purification. The relationship

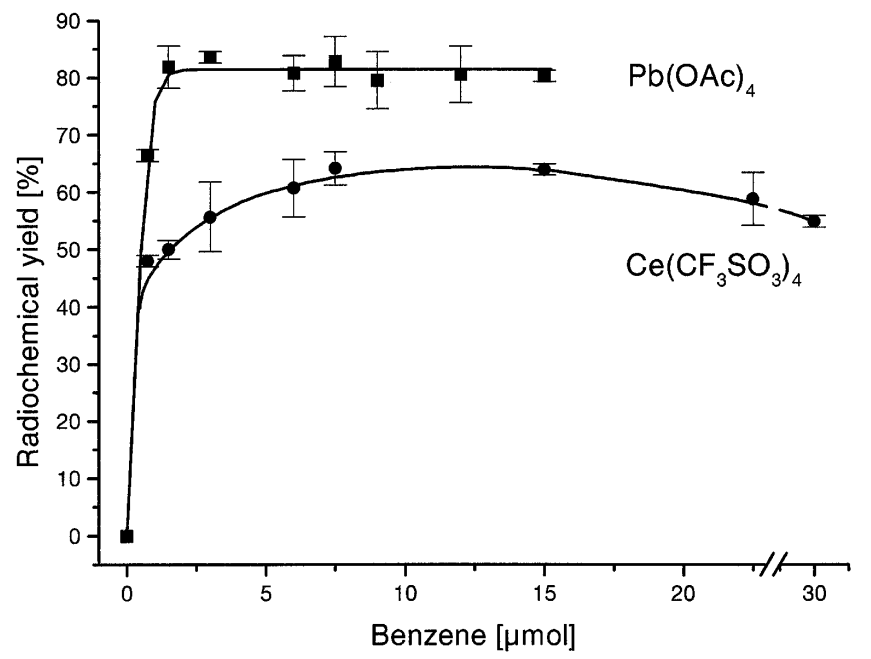

Fig. 3. Dependence of the radiochemical yield of $\left[{ }^{131} \mathrm{I}\right]$ iodobenzene on the amount of benzene. Reaction conditions: $6.75 \mu \mathrm{mol} \mathrm{Pb}\left(\mathrm{CH}_{3} \mathrm{CO}_{2}\right)_{4}$, $22.5 \mu \mathrm{mol} \mathrm{Ce}\left(\mathrm{CF}_{3} \mathrm{SO}_{3}\right)_{4}, 0.3 \mathrm{~mL}$ TFA, $15 \mathrm{~min}$ at RT.

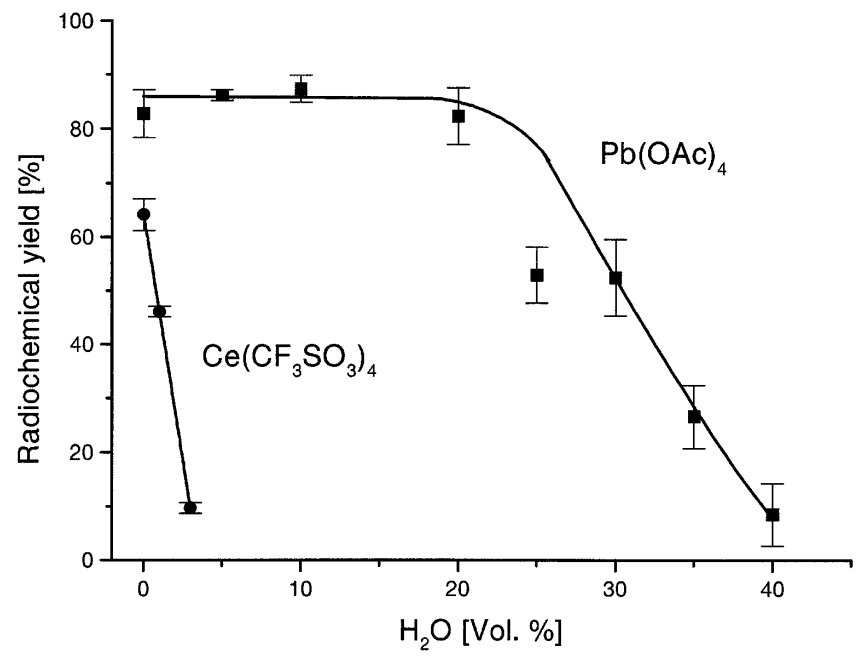

Fig. 4. Dependence of the radiochemical yield of $\left[{ }^{131} I\right]$ iodobenzene on the amount of added water. Reaction conditions: $6.75 \mu \mathrm{mol}$ $\mathrm{Pb}\left(\mathrm{CH}_{3} \mathrm{CO}_{2}\right)_{4}, 22.5 \mu \mathrm{mol} \mathrm{Ce}\left(\mathrm{CF}_{3} \mathrm{SO}_{3}\right)_{4}, 7.5 \mu \mathrm{mol}$ benzene, $0.3 \mathrm{~mL}$ TFA $+\mathrm{H}_{2} \mathrm{O}, 15 \mathrm{~min}$ at RT.

between the amount of benzene and the radiochemical yield of $\left[{ }^{131} \mathrm{I}\right]$ iodobenzene is illustrated in Fig. 3. Using lead(IV) acetate an amount as small as $2 \mu \mathrm{mol}$ of benzene in $0.3 \mathrm{~mL}$ TFA resulted in an optimum yield of about $80 \%$. In the case of cerium(IV) triflate a higher educt amount of about $10 \mu \mathrm{mol}$ had to be used to obtain the maximum yield of $64 \%$. This indicates adsorption on the solid metal salt either of the educt, the radioiodide, the formed iodinating species or, at least, a lower ratio of educt to electrophile than with lead(IV) acetate.

The effect of water on the radioiodination efficiency is shown in Fig. 4. Working in the presence of water is especially advantageous for radioiodination, since drying of the normally aqueous radioiodide can be avoided and thus the risk of evaporating radioactivity is minimized. This is even more important when working with short lived iodine$120\left(\mathrm{t}_{1 / 2}=81 \mathrm{~min}\right)$ and iodine-123 $\left(\mathrm{t}_{1 / 2}=13.2 \mathrm{~h}\right)$. Fig. 4 shows that in the case of lead(IV) acetate about 20 vol.\% water $(60 \mu \mathrm{l})$ was tolerated with no decrease in the radio- 


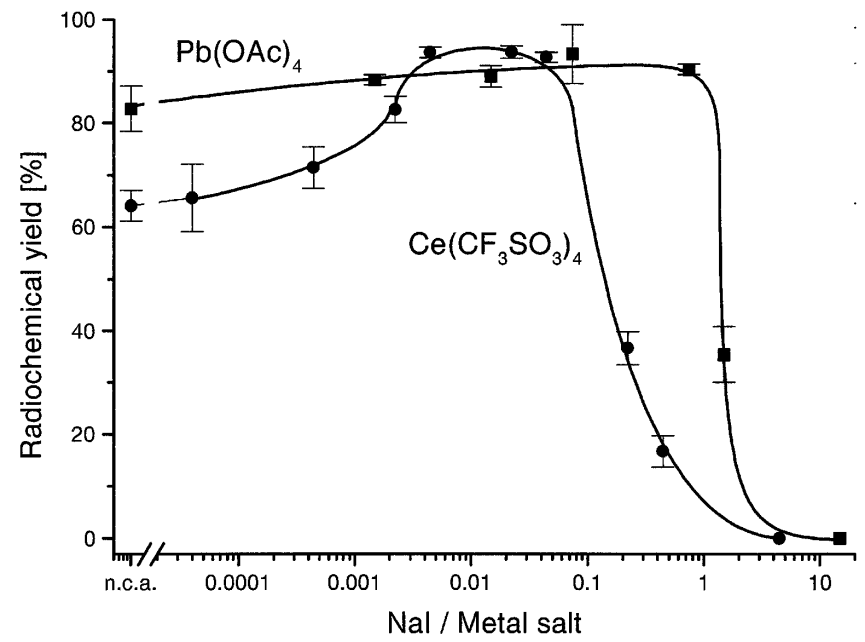

Fig. 5. Dependence of the radiochemical yield of $\left[{ }^{131} \mathrm{I}\right]$ iodobenzene on the added iodide-carrier. Reaction conditions: $6.75 \mu \mathrm{mol} \mathrm{Pb}\left(\mathrm{CH}_{3} \mathrm{CO}_{2}\right)_{4}$, $22.5 \mu \mathrm{mol} \mathrm{Ce}\left(\mathrm{CF}_{3} \mathrm{SO}_{3}\right)_{4}, 7.5 \mu \mathrm{mol}$ benzene, $0.3 \mathrm{~mL}$ TFA, $15 \mathrm{~min}$ at RT.

chemical yield. Due to the dilution of TFA the radiochemical yield decreases at higher amounts of water.

In the case of cerium(IV) triflate addition of water led to a dramatic decrease of the radiochemical yield; with only 5 vol. \% it reduces to $10 \%$. Radioiodination of the non-activated benzene and also of the weakly deactivated chlorobenzene was only possible under water-free conditions, while the radioiodination of the strongly and weakly activated arenes phenol, anisole and toluene was not influenced by addition of 10 vol. $\%$ water (data not shown here). Since cerium(IV) triflate can be prepared in situ by electrochemical oxidation of cerium(III) triflate in aqueous trifluoromethanesulfonic acid [24] this effect cannot be explained by the decomposition of cerium(IV) triflate in water. Nevertheless, the radioiodination of benzene is inhibited probably by interactions between the highly reactive oxidizing agent and the added water. It must be speculated, that the concentration of the electrophilic iodination species is reduced in the presence of water. Therefore it is recommendable to dry the radioiodide prior to the in situ oxidation step of the radiosynthesis with cerium(IV) triflate.

The effect of added NaI carrier on the radiochemical yield is shown in Fig. 5. No $\mathrm{NaBr}$ was added as non-isotopic-carrier in the study on carrier-dependence except for the n.c.a. condition with lead(IV) acetate. Using lead(IV) acetate the radiochemical yield of $\left[{ }^{131} \mathrm{I}\right]$ iodobenzene showed a slight increase up to a $\mathrm{NaI} / \mathrm{Pb}(\mathrm{OAc})_{4}$ ratio of 1 . For sta- tistical reasons the radiochemical yield decreased at higher $\mathrm{NaI} / \mathrm{Pb}(\mathrm{OAc})_{4}$ ratios. Since the radiochemical yield of $\left[{ }^{131} \mathrm{I}\right]$ iodobenzene is almost unaffected by the addition of small amounts of iodide carrier, it appears, that its addition does not change the reaction mechanism. The use of metal salts causes an in situ oxidation of n.c.a. radioiodide followed by an electrophilic aromatic substitution. This should not be influenced by small amounts of carrier iodide, what is in agreement with the results depicted in Fig. 5.

In the case of cerium(IV) triflate, addition of carrier iodide up to a $\mathrm{NaI} / \mathrm{Ce}\left(\mathrm{CF}_{3} \mathrm{SO}_{3}\right)_{4}$ ratio of 0.02 led to a significant increase in the formation of $\left[{ }^{131} \mathrm{I}\right]$ iodobenzene with a radiochemical yield of about $93 \%$. The shape of the curve in Fig. 5 may indicate, that n.c.a. radioiodide is adsorbed on the cerium salt surface and is displaced by addition of carrier iodide. It is well known, that metal ions can efficiently be adsorbed on cerium(IV) compounds [25, 26]. On the other hand, with iodide-carrier added the transient concentration of electrophilic species formed, i.e. its ratio to the educt, is increased what may explain the increasing yields (as discussed above). Further addition of NaI above a ratio of 0.1 to the metal again decreases the obtainable radiochemical yield.

\section{Radioiodination of monosubstituted arenes}

In order to examine the influence of arene activation on the radioiodination with metal salts, various monosubstituted benzenes were used as educt. The results obtained with activated and deactivated arenes are listed in Table 1.

Using lead(IV) acetate the labelling reaction gave rise to good radiochemical yields of about $70 \%$ and $80 \%$ with the weakly activated arenes anisole and toluene, respectively. Radioiodination of non-activated benzene also led to high radiochemical yields; however, the weakly deactivated chlorobenzene could not be labelled.

Cerium(IV) triflate mediated radioiodination also gave good radiochemical yields of about $60 \%$ for all weakly activated arenes and benzene. However, with this oxidant even the n.c.a. radioiodination of the weakly deactivated chlorobenzene was possible resulting in a modest radiochemical yield of about $35 \%$. Surprisingly only the paraisomer was formed. The relatively low radiochemical yield of $\left[{ }^{131} \mathrm{I}\right]$ iodophenol indicates an oxidative decomposition of the highly activated phenol by both oxidants, since it is known that lead(IV) acetate and cerium(IV) salts can oxidize phenol derivatives to quinones [23, 27]. Radioiodinated side products, however, were not observed in the reac-

\begin{tabular}{|c|c|c|c|c|}
\hline \multirow[t]{2}{*}{ Substituent } & \multicolumn{2}{|c|}{ Lead(IV) acetate } & \multicolumn{2}{|c|}{ Cerium(IV) triflate } \\
\hline & $\begin{array}{l}\text { radiochemical } \\
\text { yield }[\%]\end{array}$ & $\begin{array}{l}\text { positional } \\
\text { selectivity [\%] }\end{array}$ & $\begin{array}{l}\text { radiochemical } \\
\text { yield }[\%]\end{array}$ & $\begin{array}{l}\text { positional } \\
\text { selectivity [\%] }\end{array}$ \\
\hline $\mathrm{OH}$ & $50.1 \pm 6.8$ & $15 / 85 \mathrm{o} / \mathrm{p}$ & $31.0 \pm 8.8$ & $20 / 80 \mathrm{o} / \mathrm{p}$ \\
\hline $\mathrm{OCH}_{3}$ & $71.9 \pm 6.8$ & $5 / 95 \mathrm{o} / \mathrm{p}$ & $59.3 \pm 2.8$ & $15 / 85 \mathrm{o} / \mathrm{p}$ \\
\hline $\mathrm{CH}_{3}$ & $80.7 \pm 3.6$ & $50 / 50 \mathrm{o} / \mathrm{p}$ & $60.0 \pm 6.9$ & $50 / 50 \mathrm{o} / \mathrm{p}$ \\
\hline $\mathrm{H}$ & $82.8 \pm 4.4$ & - & $64.1 \pm 2.9$ & - \\
\hline $\mathrm{Cl}$ & 0 & - & $35.1 \pm 1.6$ & $100 \mathrm{p}$ \\
\hline
\end{tabular}

Table 1. Radiochemical n.c.a. radioiodination yields with selected monosubstituted arenes using lead(IV) acetate and cerium(IV) triflate as oxidants.

Reaction conditions: $6.75 \mu \mathrm{mol} \mathrm{Pb}\left(\mathrm{CH}_{3} \mathrm{CO}_{2}\right)_{4}, 22.5 \mu \mathrm{mol} \mathrm{Ce}\left(\mathrm{CF}_{3} \mathrm{SO}_{3}\right)_{4}, 7.5 \mu \mathrm{mol}$ arene, $0.3 \mathrm{~mL}$ TFA, $15 \mathrm{~min}$ at RT. 
Table 2. Radioiodination yields of toluene and benzene using various metal salts as oxidants.

\begin{tabular}{|c|c|c|c|}
\hline Metal salt & $\begin{array}{l}\text { TFA- } \\
\text { soluble }\end{array}$ & $\begin{array}{l}{\left[{ }^{131} \mathrm{I}\right] \text { Iodo- }} \\
\text { toluene }{ }^{a}\end{array}$ & $\begin{array}{l}{\left[{ }^{131} \mathrm{I}\right] \text { Iodo- }} \\
\text { benzene }\end{array}$ \\
\hline $\mathrm{Pb}\left(\mathrm{CH}_{3} \mathrm{CO}_{2}\right)_{4}$ & + & $80.7 \pm 3.6$ & $82.8 \pm 4.4$ \\
\hline $\mathrm{KMnO}_{4}$ & + & $51.6 \pm 5.8$ & $6.2 \pm 1.8$ \\
\hline $\mathrm{Mn}\left(\mathrm{CH}_{3} \mathrm{CO}_{2}\right)_{3}$ & + & $64.2 \pm 1.3$ & $4.2 \pm 1.5$ \\
\hline $\mathrm{AgCF}_{3} \mathrm{SO}_{3}$ & + & $51.3 \pm 4.7$ & $13.3 \pm 6.0$ \\
\hline $\mathrm{Tl}\left(\mathrm{CF}_{3} \mathrm{CO}_{2}\right)_{3}$ & + & $73.6 \pm 1.9$ & $51.1 \pm 2.0$ \\
\hline $\mathrm{Ce}\left(\mathrm{CF}_{3} \mathrm{SO}_{3}\right)_{4}$ & - & $60.0 \pm 6.9$ & $64.1 \pm 2.9$ \\
\hline $\mathrm{RuCl}_{3}$ & - & $61.1 \pm 5.9$ & $40.1 \pm 1.1$ \\
\hline $\mathrm{FeBr}_{3}$ & - & $55.0 \pm 4.1$ & $50.8 \pm 5.0$ \\
\hline $\mathrm{K}_{2} \mathrm{Cr}_{2} \mathrm{O}_{7}$ & - & $76.1 \pm 5.9$ & $70.4 \pm 2.2$ \\
\hline
\end{tabular}

a: Positional selectivity with all metal salts: $\mathrm{o} / \mathrm{p}=50 / 50$.

Reaction conditions: $6.75 \mu \mathrm{mol}$ TFA-soluble metal salt, $22.5 \mu \mathrm{mol}$ TFA-insoluble metal salt, $7.5 \mu \mathrm{mol}$ arene, $0.3 \mathrm{~mL}$ TFA, $15 \mathrm{~min}$ at RT.

tion with phenol. All monosubstituted arenes listed in Table 2 show an ortho/para isomer distribution typical of electrophilic substitutions.

The radiochemical yields obtained in lead(IV) acetate mediated radioiodination are generally higher than those using cerium(IV) triflate; however, radioiodination of chlorobenzene on n.c.a. level is only possible with cerium(IV) triflate. This indicates, that cerium(IV) triflate mediated radioiodination could in principle lead to higher radiochemical yields, but the labelling reaction is probably inhibited because of adsorption effects resulting in a low concentration of the radioiodination species, as discussed above. This assumption is supported by the fact that addition of an amount of $0.5 \mu \mathrm{mol}$ iodide-carrier led to a significant increase of the formation of $\left[{ }^{131} \mathrm{I}\right]$ iodotoluene, $\left[{ }^{131} \mathrm{I}\right]$ iodobenzene and $\left[{ }^{131} \mathrm{I}\right]$ iodochlorobenzene with radiochemical yields of about $90 \%$, which is higher than using lead(IV) acetate under the same carrier-added reaction conditions (data not shown here). Obviously, compensation of adsorption effects on cerium(IV) triflate by addition of iodide carrier reveals its higher potential of radioiodination in comparison to lead(IV) acetate.

The correlation of electronic activation of the arenes with their electrophilic aromatic radioiodination yields is shown in Fig. 6 for both metal salts. Substituent effects are quantified by the Brown-Okamoto $\sigma^{+}$-constants for electrophilic aromatic substitutions in meta- and para-position [28]. Because of steric effects the prediction fails for the ortho position. Therefore in Fig. 6 only the radiochemical yields of the para-radioiodinated isomers are plotted against the $\sigma^{+}$-constant of the respective aromatic para-substituent. In the case of $\left[{ }^{131} \mathrm{I}\right]$ iodobenzene only the sixth part of the total radiochemical yield is considered for statistical comparison to the one para-position of the other monosubstituted arenes. The data for $\left[{ }^{131} \mathrm{I}\right]$ iodophenol were not taken into account for the calculation of the regression lines because phenol decomposes under the oxidative reaction conditions.

The slope of the regression line is negative while using both metal salts, which confirms an electrophilic reaction pathway, since the radiochemical yields of the para radioiodinated isomers are higher for arenes with electron-donating substituents $\left(\sigma^{+}<0\right)$ than for electron-withdrawing substituents $\left(\sigma^{+}>0\right)$.

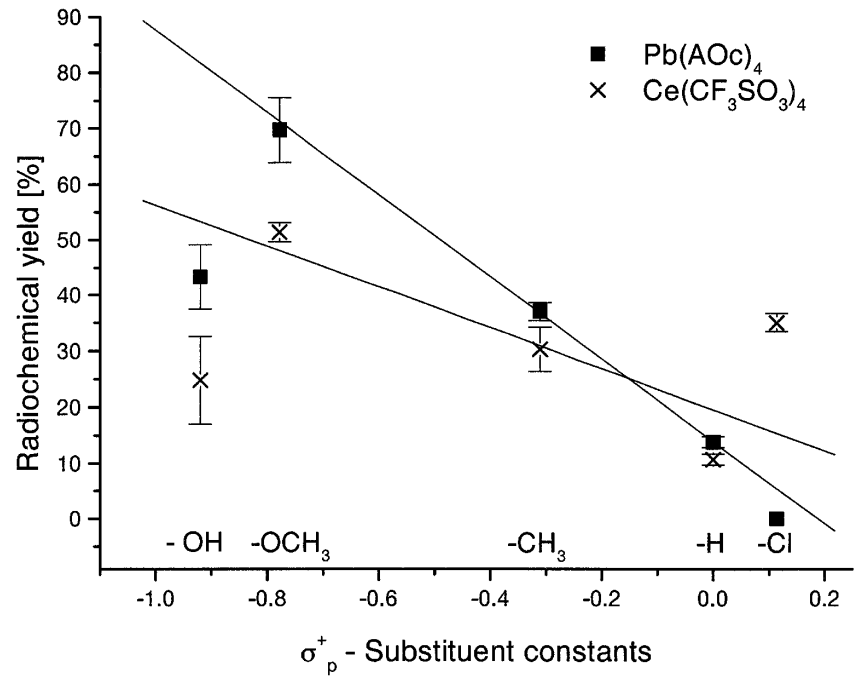

Fig. 6. Radiochemical yields of various arenes vs. Brown-Okamoto $\sigma^{+}$-para-substituent constants. The solid lines were obtained via linear regression (see text). Reaction conditions: $6.75 \mu \mathrm{mol} \mathrm{Pb}\left(\mathrm{CH}_{3} \mathrm{CO}_{2}\right)_{4}$, $22.5 \mu \mathrm{mol} \mathrm{Ce}\left(\mathrm{CF}_{3} \mathrm{SO}_{3}\right)_{4}, 7.5 \mu \mathrm{mol}$ arene, $0.3 \mathrm{~mL} \mathrm{TFA}, 15 \mathrm{~min}$ at RT.

In the case of lead(IV) acetate the linear regression $(\mathrm{y}=$ $-73.75 \pm 1.64 x+13.87 \pm 0.32)$ seems reasonable, since the correlation coefficient is very high $\left(r^{2}=1\right)$. However, the heterogeneous reaction with cerium(IV) triflate probably results in distorted radiochemical yields of the paraisomers as depicted in Fig. 6. This is supported by the questionable linear dependence $(\mathrm{y}=-36.71 \pm 24.99 \mathrm{x}+$ $19.52 \pm 8.75)$ indicated by a low correlation coefficient $\left(\mathrm{r}^{2}=0.52\right)$. Nevertheless, the higher reactivity (concentration of radioiodination species) of cerium(IV) triflate as discussed above is indicated in Fig. 6, although the bad correlation prevents absolute proof.

\section{Radioiodination of benzene and toluene using various metal salts}

After optimizing the reaction parameters for lead(IV) acetate and cerium(IV) triflate radioiodination of toluene and benzene was performed using the other TFA-soluble and TFA-insoluble metal salts mentioned above. The results are listed in Table 2.

As expected radioiodination of the weakly activated toluene generally led to higher radiochemical yields than using the non-activated benzene. The labelling of toluene gave rise to good radiochemical yields with all investigated metal salts. The highest radiochemical yields of $\left[{ }^{131} \mathrm{I}\right]$ iodotoluene of about $80 \%$ and $75 \%$, respectively, could be obtained using the TFA-soluble metal salts lead(IV) acetate and thallium(III) trifluoroacetate but also with the TFA-insoluble potassium dichromate. Radioiodination of benzene also led to good radiochemical yields except with the TFAsoluble manganese and the silver salts. In this case the oxidation power was probably not strong enough for the radioiodination of the non activated benzene. However, using the TFA-insoluble metal salts the radiochemical yields of $\left.{ }^{[131} \mathrm{I}\right]$ iodobenzene were, except with $\mathrm{RuCl}_{3}$, almost as high as that of $\left[{ }^{131} \mathrm{I}\right]$ iodotoluene. 


\section{Iodinating species}

The electrophilic aromatic iodination in the solvent TFA is well documented in preparative organic chemistry. In many cases an intermediately formed and highly reactive trifluoroacetyl hypoiodite is postulated as the iodinating species [5, 11, 29, 30]. The existence of this in situ formed iodination agent was indeed confirmed by n.m.r. investigations [29]. However, the isolation of trifluoroacetyl hypoiodite has never been documented, since it is thermally labile and decomposes to trifluoromethyl iodide and carbon dioxide [11]. This species was first postulated in 1952 by Haszeldine and Sharp in the reaction of silver trifluoroacetate and iodine in nitrobenzene [11]. Recently a Russian group studied the direct iodination of monosubstituted arenes in the presence of cobalt(III) acetate, manganese(III) acetate and ammonium cerium(IV) sulfate in TFA and also postulated trifluoroacetyl hypoiodite as the actual iodinating agent, formed according to following equation [5]:

$$
\begin{aligned}
2 \mathrm{M}^{\mathrm{n}+} & +\mathrm{I}^{-}+\mathrm{CF}_{3} \mathrm{COOH} \rightarrow 2 \mathrm{M}^{(\mathrm{n}-1)+} \\
& +\mathrm{CF}_{3} \mathrm{COOI}+\mathrm{H}^{+} .
\end{aligned}
$$

The in situ formation of trifluoroacetyl hypoiodite has also been postulated using organic $\mathrm{N}$-iodoamides in TFA like Chloramin-T (CAT), Iodogen ${ }^{\mathrm{TM}}$ (1,3,4,6-tetrachloro-3 $\alpha-6 \alpha$ diphenyl-glycoluril) or $\mathrm{N}$-iodoacetamide [29, 30]. Correspondingly, trifluoroacetyl hypoiodite was postulated as iodination agent for the n.c.a. radioiodination of tyrosine analogues and various anisole derivatives using Iodogen ${ }^{\mathrm{TM}}$ in TFA [31, 32]. Finally the in situ formation of trifluoroacetyl hypoiodite is supported by the fact, that the reaction of $\mathrm{N}$-iodosuccinimide in trifluoromethanesulfonic acid also leads to an intermediately formed iodo(I) trifluoromethanesulfonate (triflyl hypoiodite) as highly activated iodination species $[33,34]$. The existence and formation of triflyl hypoiodite has well been documented [35]. This also supports the idea of an analogous formation of trifluoroacetyl hypoiodite using $\mathrm{N}$-iodoamides in TFA.

Although the n.c.a. radioiodination agent can not be identified, the experimental facts indicate that the radioiodination of arenes using various metal salts could result in the in situ formation of a highly activated trifluoroacetyl $\left[{ }^{131} \mathrm{I}\right]$ hypoiodite as electrophilic iodination agent.

Another fact is, that the isomer distribution of the radioiodinated products of metal salts in TFA is typical of an electrophilic aromatic substitution mechanism and is identical for all metal salts used. The concentration of the iodination agent or its electrophilic potential is probably dependent on the oxidation power of the metal salt in TFA, which leads to different total radiochemical yields. The radiosynthesis could also be influenced by interactions of the iodination species with the metal salt. Using lead(IV) acetate, addition of carrier iodide has no influence on the radiochemical yield of $\left[{ }^{131} \mathrm{I}\right]$ iodobenzene. Obviously, the reaction mechanism does not change in the concentration range studied, which indicates that the postulated hypoiodite could also be valid on n.c.a. level. In the case of cerium(IV) triflate carrier iodide increases the formation of $\left[{ }^{131} \mathrm{I}\right]$ iodobenzene but probably due to compensation of adsorption effects. Furthermore, high radiochemical yields could only be obtained in TFA as solvent. Radioiodination of benzene in the presence of other strong acids like perchloric acid only led to radiochemical yields of about $15 \%$ using both types of metal salts.

\section{Conclusion}

In conclusion, the use of metal salts in TFA allows the direct electrophilic n.c.a. radioiodination of several weakly activated aromatic compounds with high radiochemical yields in a one-pot synthesis. The labelling reactions can be performed within a very short reaction time of a few minutes at room temperature with radiochemical yields up to $80 \%$ and $65 \%$ using TFA-soluble lead(IV) acetate and TFA-insoluble cerium(IV) triflate, respectively. Even n.c.a. radioiodination of the weakly deactivated chlorobenzene is possible. Radiochemical yields can also be increased in a given case by addition of iodide-carrier. The effect of arene substituents is typical for a direct electrophilic radioiodination and the labelled products correspondingly show an ortho/para isomer substitution pattern. This is not influenced by the type of metal salts used. This, together with the data in the literature suggests that trifluoroacetyl $\left[{ }^{131} \mathrm{I}\right]$ hypoiodite is the reacting electrophilic species.

Both methods are very effective and lead to higher radiochemical yields than $\mathrm{CAT}$ or $\mathrm{N}$-chlorosuccinimide in trifluoroacetic acid anhydride or Iodogen ${ }^{\mathrm{TM}}$ in TFA. The metal salts are easy to separate by filtration or simple solid phase extraction. The application of the examined metal salts as oxidants for the direct n.c.a. radioiodination of complex molecules also represents a useful alternative to other labelling systems like copper(I) assisted radioiodination or radioiodo-destannylation although these reactions are generally position-selective. This is especially true in cases where the target molecule is either sensitive to the reaction conditions or the stannylated precursor compound is not available. At least for quick preliminary radioiodination of aromatic hydrocarbons the direct method holds advantage, which can later be substituted by the more sophisticated precursors for position specific labelling if suitability of the tracer has been proven. The large selection and the different oxidative power of the metal salts even allows the radioiodination of pharmaceutically interesting compounds which are sensitive to oxidative decomposition. Of course, precursor and radioiodinated product must be stable in TFA.

\section{References}

1. Bourguignon, M. H., Pauwels, E. K. J., Loch, C., Mazière, B.: Eur. J. Nucl. Med. 24, 331 (1997).

2. Dewanjee, M. K.: Radioiodination: Theory, Practice and Biomedical Applications. Kluver Academic, Boston (1991).

3. Coenen, H. H., Moerlein, S. M., Stöcklin, G.: Radiochim. Acta 34, 47 (1983).

4. Seevers, R. H., Counsell, R. E.: Chem. Rev. 82, 575 (1982).

5. Makhonkov, D. I., Cheprakov, A. V., Rodkin, M. A., Beletskaya, I. P.: J. Org. Chem. USSR 21, 1003 (1986).

6. Krassowaska-Swiebocka, B., Lulinski, P., Skulski, L.: Synthesis 926 (1995).

7. Serguchev, Yu. A., Davydova, V. G., Makhonkov, D. I., Cheprakov, A. V., Beletskaya I. P.: J. Org. Chem. USSR 21, 1841 (1985). 
8. Sugiyama, T.: Bull. Chem. Soc. Jpn. 54, 2847 (1981).

9. Taylor, E. C., McKillop, A., Kienzle, F., Robey, R. L., Hunt, J. D.: J. Am. Chem. Soc. 93, 4845 (1971).

10. Kobayashi, Y., Kumadaki, I., Yoshida, T.: J. Chem. Research (S) 215 (1977).

11. Haszeldine, R. N., Sharpe, A. G.: J. Chem. Soc. 993 (1952).

12. Chaikovskii, V. K., Novikov, A. N.: J. Appl. Chem. (USSR) 57, 121 (1984).

13. Lulinski, P., Skulski, L.: Bull. Chem. Soc. Jpn. 70, 1665 (1997).

14. Grigorev, M. G., Buketova, I. A., Poleshchikov, P. F.: Izv. Vyssh. Uchebn. Zaved. Khim. Khim. Tekhnol. 30, 22 (1987).

15. Benzon, D.: Mechanisms of Oxidation by Metal Ions, Elsevier, New York (1976) p. 44.

16. Mennicke, E., Henneken, H., Holschbach, M. H., Coenen, H. H. : J. Labelled Comp. Radiopharm. 40, 107 (1997).

17. Mennicke, E., Hennecken, H., Holschbach, M. H., Coenen, H. H.: Eur. J. Nucl. Med. 25, 843 (1998).

18. Knust, E. J., Schüller, M.: J. Chromatogr. 114, 207 (1975)

19. Meyer, G.-J., Rössler, K., Stöcklin, G.: Radiochim. Acta 24, 81 (1977)

20. Beletskaya, I. P., Demyanov, P. I., Makhonkov, D. I., Zeldis, I. M., Burenko, S. N.: J. Org. Chem. USSR. 17, 583 (1981).
21. Makhon'kov, D. I., Cheprakov, A. V., Rodkin, M. A., Milchenko, A. Yu., Beletskaya, I. P.: J. Org. Chem. USSR. 22, 24 (1986).

22. Rück, K., Kunz, H.: J. prakt. Chem. 336, 470 (1994).

23. Ho, T.-L.: Synthesis 347 (1973).

24. Kreh, R. P., Spotnitz, R. M., Lundquist, J. T.: Tetrahedron Lett. 28, 1067 (1987).

25. Mishra, S. P., Singh, V. K.: Radiochim. Acta 68, 251 (1995).

26. Mishra, S. P., Singh, V. K.: Appl. Radiat. Isot. 46, 75 (1995).

27. March, J.: Advanced Organic Chemistry; 4th ed., John Wiley \& Sons, Inc., New York (1992) p. 1171.

28. Brown, H. C., Okamoto, Y. J.: Am. Chem. Soc. 80, 4979 (1958).

29. Goosen, A., Lovelock, J., Taljaard, B.: J. South Afr. Chem. Inst. 28, 235 (1975).

30. Goosen, A., Taljaard, B.: J. South Afr. Chem. Inst. 28, 196 (1975).

31. Krummeich, C., Holschbach, M. H., Stöcklin, G. : Appl. Radiat. Isot. 45, 929 (1994).

32. Krummeich, C., Holschbach, M. H., Stöcklin, G. : Appl. Radiat. Isot. 47, 489 (1996).

33. Olah, G. A., Wang, Q., Sandford, G., Surya Prakash, G. K.: J. Org. Chem. 58, 3194 (1993).

34. Mennicke, E., Holschbach, M. H., Coenen, H. H.: J. Labelled Comp. Radiopharm., in press.

35. Dalziel, J. R., Aubke, F.: Inorg. Chem. 12, 2707 (1973). 